\title{
Electrospun porous cellulose acetate fibers from volatile solvent mixture
}

\author{
Asli Celebioglu, Tamer Uyar* \\ UNAM-Institute of Materials Science E Nanotechnology, Bilkent University, Ankara, 06800, Turkey
}

\section{A R T I C L E I N F O}

Article history:

Received 13 January 2011

Accepted 11 April 2011

Available online 20 April 2011

\section{Keywords:}

Electrospinning

Cellulose acetate

Nanofiber

Porous

Ribbon-like

\begin{abstract}
A B S T R A C T
Electrospun porous cellulose acetate (CA) fibers were produced from highly volatile binary solvent system; dichloromethane(DCM)/acetone. The morphology and porous structure of CA fibers were highly dependent on DCM/acetone ratio and the concentration of the solutions. Ribbon-like porous CA fibers were obtained from $5 \%(\mathrm{w} / \mathrm{v})$ to $10 \%(\mathrm{w} / \mathrm{v})$ polymer solutions depending on the DCM/acetone ratio; $1 / 1,2 / 1,3 / 1$ and 9/1 (v/v). Using higher DCM/acetone ratio resulted in bead-free fibers from less concentrated polymer solutions due to the high viscosity of the solutions, in addition, more porous CA fibers were obtained owing to the high volatility of DCM.
\end{abstract}

(C) 2011 Elsevier B.V. All rights reserved.

\section{Introduction}

Electrospinning is a simple and versatile technique for producing nanofibers/nanowebs having very large surface area to volume ratio and these nanofibers/nanowebs are quite applicable in many areas including filtrations, biotechnology, textiles, etc. [1-4]. Nanofibers having nanoporous structures are particularly attractive for filtration purposes [3-5]. Electrospun nanofibers with highly porous morphologies can be obtained by applying various methodologies such as; using high boiling point/low boiling point binary solvent mixtures [6], using solvent/non-solvent mixtures [7-9], electrospinning of polymers in a humid environment [10], or post-treatments of electrospun polymer blend or composite nanofibers by selectively removing one of the components $[11,12]$.

Cellulose acetate (CA) is a derivative of cellulose which can be electrospun into ultrafine fibers for the possible applications in filtration and biomedical areas $[13,14]$. It has been shown that the solvent system used for the electrospinning of CA plays an important role for obtaining uniform CA fibers $[15,16]$. In most cases, binary solvent mixtures consist of high boiling point solvents (DMAc, acetic acid, water) and relatively low boiling point solvents (acetone, $\mathrm{MeOH}$ ) were used $[15,16]$. It was reported that mixture of DMAc/acetone is the most appropriate solvent systems for obtaining bead-free uniform electrospun CA fibers [15]. Porous electrospun CA fibers were also obtained by electrospinning of bicomponent fibers and selectively removing one of the components [12].

In this study, we used a new binary solvent system; dichloromethane (DCM)/acetone, for the electrospinning of CA fibers. Both DCM and acetone are highly volatile solvents, therefore we anticipated to obtain CA fibers with different morphologies. Indeed, we produced highly

\footnotetext{
* Corresponding author. Tel.: +90 3122903571; fax: +90 3122664365.

E-mail addresses: tamer@unam.bilkent.edu.tr, tameruyar@gmail.com (T. Uyar).
}

porous ribbon-like CA fibers from DCM/acetone binary solvent system and we observed that the morphology and the porous structure of the CA fibers were very much depending on the DCM/acetone ratio.

\section{Experimental}

The dichloromethane (DCM) (extra pure), acetone (pure), N,Ndimethylacetamide (DMAc) (99\%) and cellulose acetate (CA) (Mw 30,000 ) were purchased from Sigma-Aldrich. The materials were used without any purification.

Homogenous solutions were obtained by dissolving CA in DCM/ acetone binary solvent mixture. The DCM/acetone ratios of 1/1, 2/1, 3/1 and $9 / 1(\mathrm{v} / \mathrm{v})$ and the CA concentrations of $5 \%, 7.5 \%$ and $10 \%(\mathrm{w} / \mathrm{v})$ were used. In addition, $10 \%(\mathrm{w} / \mathrm{v})$ of CA solution in DMAc/acetone $(2 / 1, \mathrm{v} / \mathrm{v})$ was also prepared for comparison. The CA solutions were electrospun by using metallic needle syringe (inner diameter $=0.45 \mathrm{~mm}$ ) which was fixed horizontally on the syringe pump (Model: SP 101IZ, WPI). Matsusada Precision (AU Series, Japan) was used as a high voltage power supply. The electrospinning parameters were as follows: applied voltage $=15 \mathrm{kV}$, feed rate $=1 \mathrm{ml} / \mathrm{h}$ and tip-to-collector distance $=$ $10 \mathrm{~cm}$. Electrospun nanofibers were deposited on a grounded stationary cylindrical metal collector covered by a piece of aluminum foil. The electrospinning process was carried out in enclosed Plexiglas box and at $22{ }^{\circ} \mathrm{C}$ at $30 \%$ relative humidity.

The viscosity measurements were performed at a constant shear rate of $1001 / \mathrm{s}$ at $22{ }^{\circ} \mathrm{C}$ by using Anton Paar Physica MCR 301 rheometer. The conductivity of the solutions was measured with Multiparameter meter InoLab® Multi 720 (WTW) at $22^{\circ} \mathrm{C}$.

The morphology and the diameter of the CA fibers were investigated by using scanning electron microscope (SEM) (FEI - Quanta 200 FEG) and atomic force microscope (AFM) (PSIA - XE-100E). Samples were 
coated with $5 \mathrm{~nm} \mathrm{Au} / \mathrm{Pd}$ prior to SEM imaging. The fiber diameter ranges were determined from the SEM images and around 100 fibers were analyzed. The AFM imaging of the fibers collected on a glass microscope slide was performed in intermittent contact mode in air with a scan rate of $0.1 \mathrm{~Hz}$. TAP 300 (Budget Sensors) type of cantilever which has resonant frequency $=200-400 \mathrm{kHz}$ and force constant $=20-75 \mathrm{~N} / \mathrm{m}$ was used. The 3D representation and the roughness graph of the fibers were obtained by using XEI software.

\section{Results and discussion}

The electrospinning of CA fibers was carried out by using DCM/ acetone binary solvent system having different DCM/acetone ratios of 1 / $1,2 / 1,3 / 1$ and $9 / 1(\mathrm{v} / \mathrm{v})$. The concentrations of the CA solutions used were $5 \%, 7.5 \%$ and $10 \%(\mathrm{w} / \mathrm{v})$. The characteristics of CA solutions and the morphology of the resulting electrospun CA fibers are summarized in Table 1. Higher concentration of CA solutions (from $5 \%$ to $10 \%(w / v)$ ) resulted in higher solution viscosity due to the higher number of entanglements and overlapping between the polymer chains. In addition, it was found that the viscosity of CA solutions having same weight percentage was higher as the DCM/acetone ratio increased from $1 / 1$ to $9 / 1(\mathrm{v} / \mathrm{v})$. The solution conductivity was decreased as the DCM/ acetone ratio increased from $1 / 1$ to $9 / 1(\mathrm{v} / \mathrm{v})$. The addition of CA caused a small decrease in solution conductivity; yet, the solution conductivity was more or less same for the solutions having different concentrations $(5 \%, 7.5 \%$ and $10 \%(\mathrm{w} / \mathrm{v}))$ but same $\mathrm{DCM} /$ acetone ratio.

The representative SEM images of electrospun CA fibers obtained from $5 \%, 7.5 \%$ and $10 \%(\mathrm{w} / \mathrm{v})$ polymer solutions in different DCM/ acetone ratios are shown in Fig. 1. It was observed that the morphology of the electrospun CA fibers greatly depends on the polymer concentration and the DCM/acetone ratio. Electrospinning of $5 \%(\mathrm{w} / \mathrm{v})$ CA solution in $1 / 1(\mathrm{v} / \mathrm{v})$ DCM/acetone yielded only irregular beads. Increasing the CA concentration to $7.5 \%(\mathrm{w} / \mathrm{v})$ resulted in beaded fibers and bead-free fibers in the range of $0.3-1.0 \mu \mathrm{m}$ were obtained from $10 \%$ $(\mathrm{w} / \mathrm{v})$ CA solution. The transition from beads to beaded fibers and finally

Table 1

Properties of cellulose acetate (CA) solutions and the resulting electrospun fibers.

\begin{tabular}{|c|c|c|c|c|c|}
\hline Solvent & $\begin{array}{l}\% \mathrm{CA} \\
(\mathrm{w} / \mathrm{v})\end{array}$ & $\begin{array}{l}\text { Viscosity } \\
\text { (Pa.s) }\end{array}$ & $\begin{array}{l}\text { Conductivity } \\
(\mu \mathrm{S} / \mathrm{cm})\end{array}$ & $\begin{array}{l}\text { Fiber } \\
\text { morphology }\end{array}$ & $\begin{array}{l}\text { Fiber diameter } \\
\text { range }(\mu \mathrm{m})\end{array}$ \\
\hline $1 / 1(\mathrm{v} / \mathrm{v})$ & 0 & - & 1.9 & - & - \\
\hline \multirow[t]{3}{*}{ DCM/acetone } & 5 & 0.00365 & 1.8 & Beads only & - \\
\hline & 7.5 & 0.0175 & 1.8 & Beaded fibers & - \\
\hline & 10 & 0.0549 & 1.7 & $\begin{array}{l}\text { Ribbon-like } \\
\text { bead-free } \\
\text { fibers }\end{array}$ & $0.3-1.0$ \\
\hline $2 / 1(\mathrm{v} / \mathrm{v})$ & 0 & - & 1.4 & - & - \\
\hline \multirow[t]{3}{*}{ DCM/acetone } & 5 & 0.00475 & 0.9 & Beaded fibers & - \\
\hline & 7.5 & 0.0238 & 0.8 & $\begin{array}{l}\text { Ribbon-like } \\
\text { bead-free } \\
\text { fibers }\end{array}$ & $0.5-1.5$ \\
\hline & 10 & 0.0719 & 0.7 & $\begin{array}{l}\text { Ribbon-like } \\
\text { bead-free } \\
\text { fibers }\end{array}$ & $0.75-1.35$ \\
\hline $3 / 1(\mathrm{v} / \mathrm{v})$ & 0 & - & 1.0 & - & - \\
\hline \multirow[t]{3}{*}{ DCM/acetone } & 5 & 0.00702 & 0.6 & Beaded fibers & - \\
\hline & 7.5 & 0.0373 & 0.5 & $\begin{array}{l}\text { Ribbon-like } \\
\text { bead-free } \\
\text { fibers }\end{array}$ & $0.75-2.5$ \\
\hline & 10 & 0.0876 & 0.4 & $\begin{array}{l}\text { Ribbon-like } \\
\text { bead-free } \\
\text { fibers }\end{array}$ & $1.0-2.5$ \\
\hline $9 / 1(v / v)$ & 0 & - & 0.6 & - & - \\
\hline \multirow[t]{3}{*}{ DCM/acetone } & 5 & 0.011 & 0.2 & $\begin{array}{l}\text { Ribbon-like } \\
\text { bead-free } \\
\text { fibers }\end{array}$ & $1.5-3.5$ \\
\hline & 7.5 & 0.0493 & 0.2 & $\begin{array}{l}\text { Ribbon-like } \\
\text { bead-free } \\
\text { fibers }\end{array}$ & $3.5-7.0$ \\
\hline & 10 & 0.194 & 0.2 & - & - \\
\hline
\end{tabular}

bead-free fibers was observed as the polymer concentration was increased which is due to the higher polymer chain entanglements in the solution and this is very essential to maintain the continuity of the jet during the electrospinning process for uniform fiber formation [1].

In the case of $2 / 1(\mathrm{v} / \mathrm{v}) \mathrm{DCM} /$ acetone, electrospinning of $5 \%(\mathrm{w} / \mathrm{v}) \mathrm{CA}$ solution resulted in beaded fibers and bead-free fibers were obtained from $7.5 \%$ and $10 \%(\mathrm{w} / \mathrm{v})$ CA solutions. Very similar behavior was observed for $3 / 1(\mathrm{v} / \mathrm{v})$ DCM/acetone, that is, 5\% (w/v) CA solution yielded fibers having very few beaded structure and bead-free fibers were obtained when $7.5 \%$ and $10 \%(\mathrm{w} / \mathrm{v}$ ) CA solutions were electrospun. In the case of $9 / 1(\mathrm{v} / \mathrm{v}) \mathrm{DCM} /$ acetone, bead-free fibers were obtained from $5 \%$ and $7.5 \%(\mathrm{w} / \mathrm{v})$ CA solutions, but, we could not able to electrospun $10 \%(\mathrm{w} / \mathrm{v}$ ) CA solution due to its very high viscosity.

Overall, it was observed that CA solution at lower concentration $(5 \%, w / v)$ yielded beaded fibers, however, as the DCM/acetone ratio increased from $1 / 1$ to $9 / 1(\mathrm{v} / \mathrm{v})$, it was measured that CA solutions have higher viscosity and therefore yielded bead-free uniform fibers from less concentrated solutions ( $5 \%$ and $7.5 \%, \mathrm{w} / \mathrm{v}$ ). In addition, higher DCM/acetone ratio yielded thicker CA fibers because of the less stretching of the jet since these solutions have high viscosity and low conductivity values (Table 1) [1]

Interestingly, significant morphological variations were observed for CA fibers obtained from the same polymer concentrations but having different DCM/acetone ratios. The electrospun CA fibers have ribbonlike structures. The formation of ribbon-like fibers is commonly observed when highly volatile solvent systems were used for the electrospinning $[17,18]$. Ribbon-like fibers are formed by the collapse of a tube-like fiber skin due to a rapid vaporization of solvent from the inside the fiber and atmospheric pressure tend to collapse the tube formed by the skin as the solvent evaporated [17]. In the case of beads, irregular shapes were obtained since the skin on the bead also collapsed due to the rapid escape of the solvent from the inside. Here, a similar behavior was observed for CA fibers when electrospun from DCM/ acetone. CA fibers have shown mixture of both ribbon-like and circular fiber structures (Fig. 1B-C and E-F) in the case of 1/1 and 2/1 (v/v) DCM/ acetone ratio where the DCM content was low, however, increasing the DCM/acetone ratio to $3 / 1$ and $9 / 1(\mathrm{v} / \mathrm{v})$ resulted in ribbon-like fibers only (Fig. $1 \mathrm{G}-\mathrm{K}$ ). DCM has a low boiling point (bp: $40^{\circ} \mathrm{C}$ ) and high vapor pressure $\left(340 \mathrm{mmHg}\right.$, at $20^{\circ} \mathrm{C}$ ) when compared to acetone (bp: $56^{\circ} \mathrm{C}$, and vapor pressure: $184 \mathrm{mmHg}$, at $20^{\circ} \mathrm{C}$ ), therefore, ribbon-like fibers were produced due to the fast evaporation of DCM.

Another interesting feature of CA fibers was the porous structure. The fast evaporation of solvent gives rise to local phase separation, and the solvent-rich regions transform into pores during the electrospinning process. The SEM images of electrospun CA fibers with higher magnifications are given in Fig. 2. It was observed that, the higher the content of DCM in the solvent system, the more porous structure was obtained. The porous structure was due to the rapid evaporation of highly volatile DCM and a subsequent rapid solidification of CA polymer chains during the electrospinning process. It was also observed that at lower polymer concentration (e.g.: $5 \%(\mathrm{w} / \mathrm{v})$ ), more porous structure were obtained compared to high polymer concentration since the presence of higher amount of solvent results in more porous structure. A closer examination with AFM (Fig. 3) indicated that fiber surfaces are much rougher and having pores with higher depth as the DCM content was higher in the solution. The depth of the pores was around $10-15 \mathrm{~nm}$ for CA fibers obtained from $1 / 1(\mathrm{v} / \mathrm{v}) \mathrm{DCM} /$ acetone whereas the depth of the pores increased up to around $50 \mathrm{~nm}$ for $9 / 1(\mathrm{v} / \mathrm{v}) \mathrm{DCM} /$ acetone ratio.

The replacement of DCM by a solvent with high boiling point such as DMAc eliminated the pore formation. When DMAc/acetone $(2 / 1, v / v)$ solvent system was used, we obtained smooth fibers without the presence of porous structure, in addition, the fibers were round instead of ribbon-like structure (see supplementary material). Therefore, the reason for porous and ribbon-like structure for CA fibers was because of the highly volatile nature of DCM. 


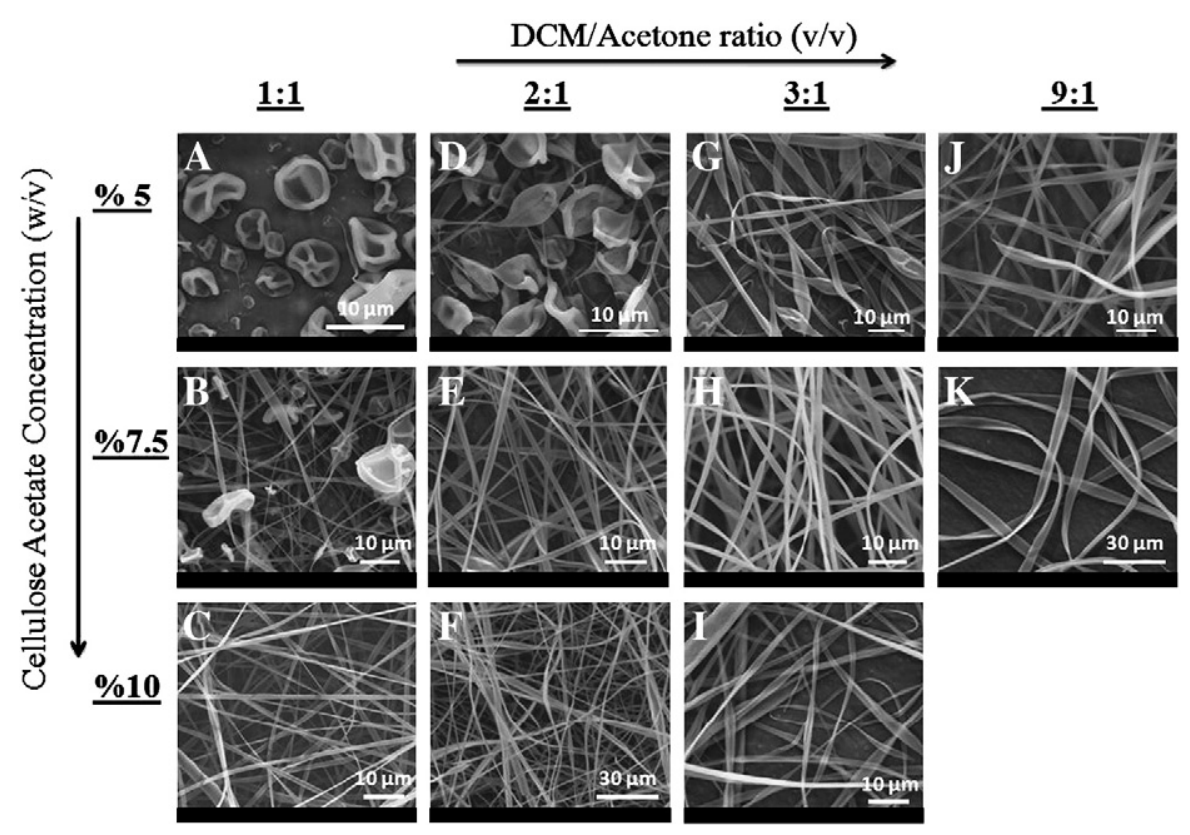

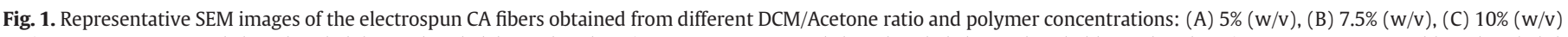

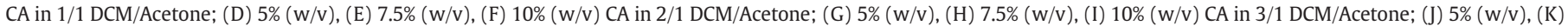
$7.5 \%(\mathrm{w} / \mathrm{v}) \mathrm{CA}$ in $9 / 1 \mathrm{DCM} /$ Acetone.

\section{Conclusion}

Electrospun porous and ribbon-like CA fibers were obtained when highly volatile DCM/acetone binary solvent system was used. Electrospinning of CA from DCM/acetone having different volume ratios (1/1, $2 / 1,3 / 1$ and $9 / 1(\mathrm{v} / \mathrm{v})$ ) and having different polymer concentrations ( $5 \%$, $7.5 \%$ and $10 \%(\mathrm{w} / \mathrm{v}))$ resulted in fibers with different morphologies and porous structures. The morphology and the porous structure of the CA fibers were very much depending on the ratio of DCM in the DCM/ acetone binary solvent system. Using higher DCM/acetone ratio yielded bead-free fibers from less concentrated polymer solutions due to the high viscosity of the solutions, in addition, more porous fibers were obtained due to the high volatility of DCM. Such porous ultrafine CA fibers would be quite interesting for the application areas such as filtration due to their very high surface to volume ratio.

Supplementary materials related to this article can be found online at doi:10.1016/j.matlet.2011.04.039.

\section{Acknowledgment}

State Planning Organization (DPT) of Turkey is acknowledged for the support of UNAM-Institute of Materials Science and Nanotechnology. Dr. Uyar acknowledges Marie Curie International Reintegration Grant (IRG)

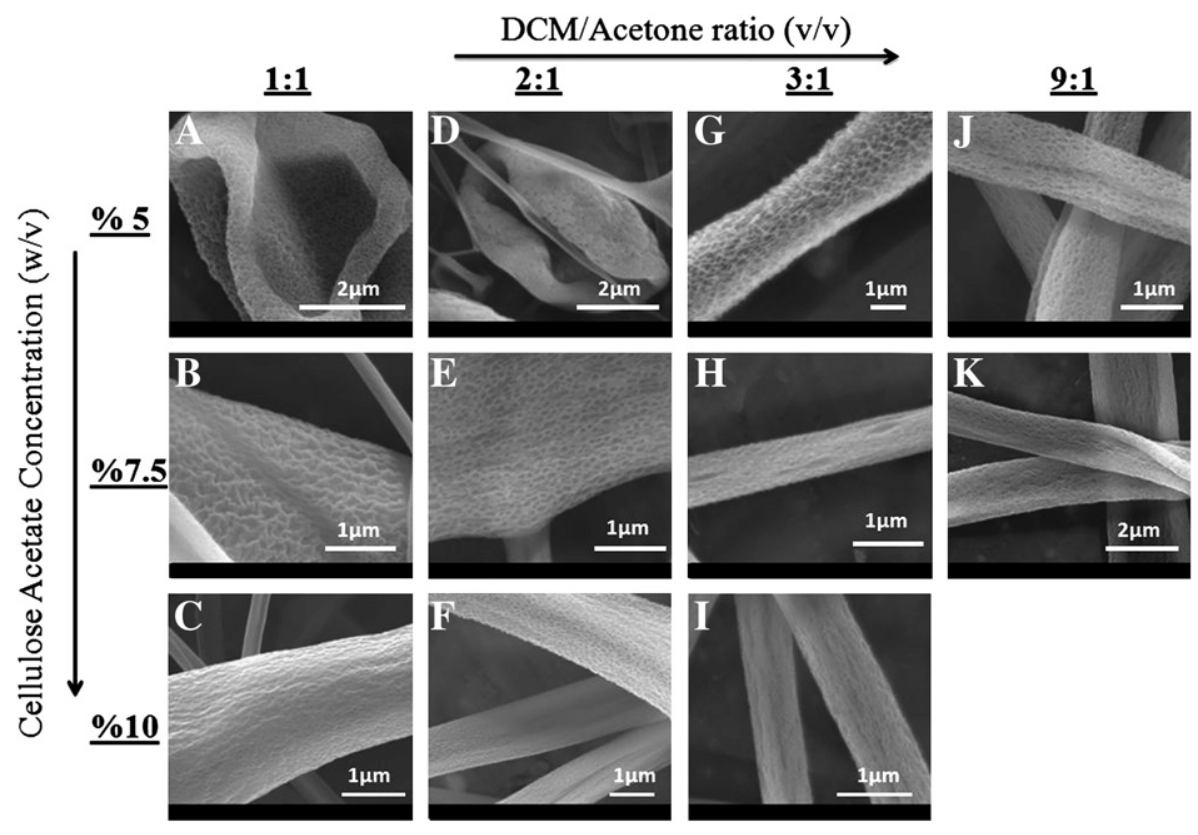

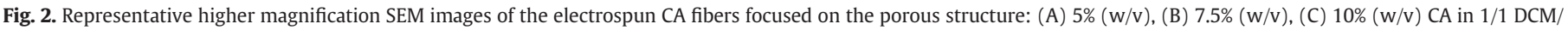

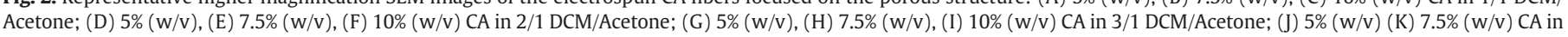
9/1 DCM/Acetone. 
A
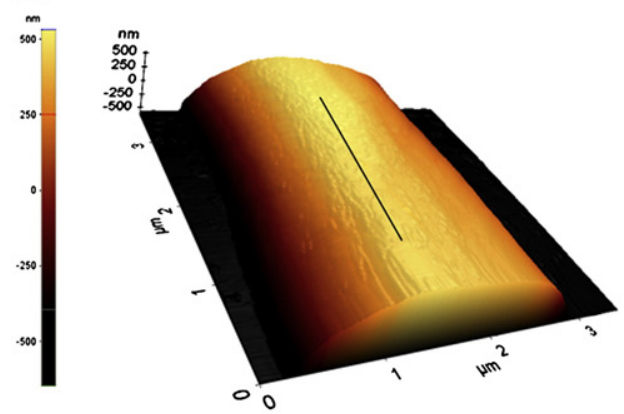

C

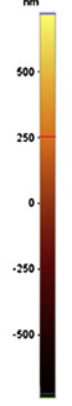

$\mathbf{E}$

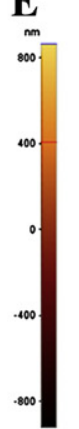

$\mathrm{nm}$
500
250
-250
-500

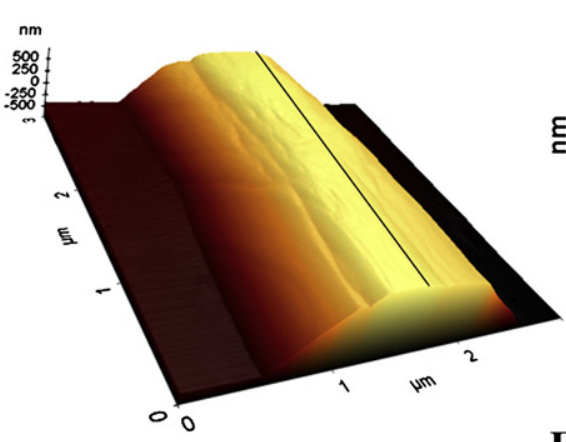

F

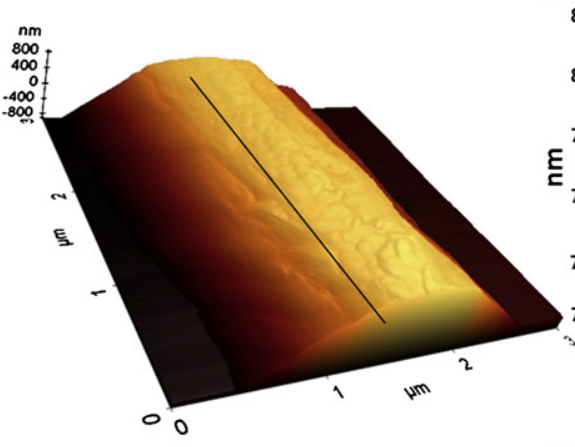

G

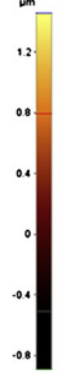

H

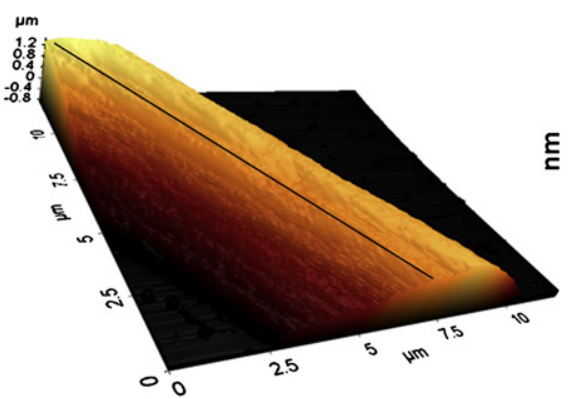

B

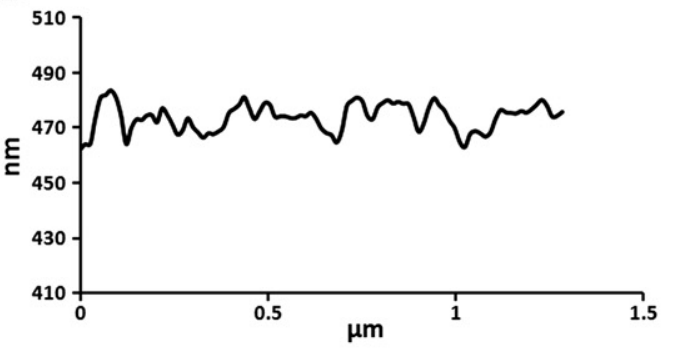

D

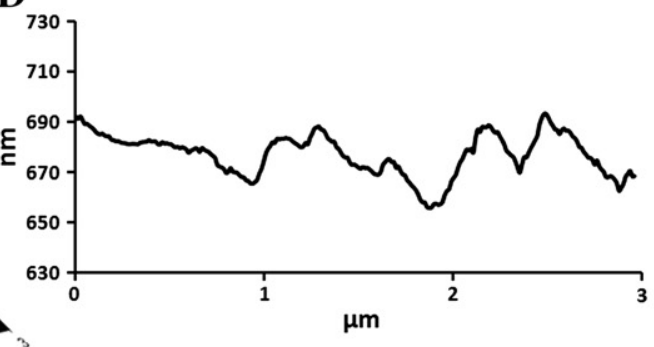

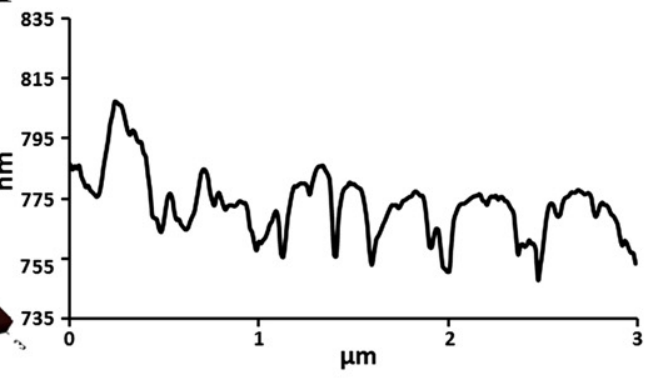

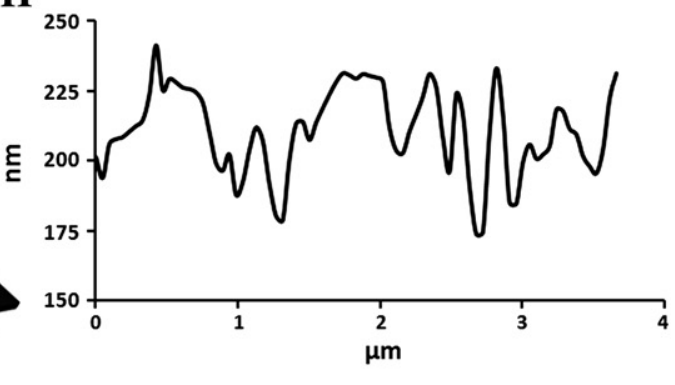

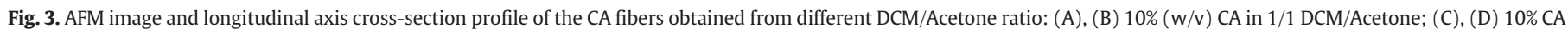
in 2/1 DCM/Acetone; (E), (F) 10\% CA in 3/1 DCM/Acetone; (G), (H) 7.5 CA in 9/1 DCM/Acetone.

for funding NANOWEB (PIRG06-GA-2009-256428) project. A. Celebioglu thanks TUBITAK-BIDEB for national graduate study scholarship.

\section{References}

[1] Ramakrishna S. An introduction to electrospinning and nanofibers. World Scientific Pub Co Inc 2005.

[2] Xie J, Li X, Xia Y. Macromol Rapid Commun 2008;29:1775-92.

[3] Ramakrishna S, Fujihara K, Teo W, Yong T, Ma Z, Ramaseshan R. Mater Today 2006;9: 40-50.

[4] Barhate R, Ramakrishna S. J Membr Sci 2007;296:1-8.

[5] Uyar T, Havelund R, Nur Y, Hacaloglu J, Besenbacher F, Kingshott P. J Membr Sci 2009;332:129-37.

[6] Miyauchi Y, Ding B, Shiratori S. Nanotechnology 2006;17:5151.
[7] Luo C, Nangrejo M, Edirisinghe M. Polymer 2010;51:1654-62.

[8] Yu X, Xiang H, Long Y, Zhao N, Zhang X, Xu J. Mater Lett 2010;64:2407-9.

[9] Qi Z, Yu H, Chen Y, Zhu M. Mater Lett 2009;63:415-8.

[10] Park J, Lee I. J Nanosci Nanotechnol 2010;10:3473-7.

[11] You Y, Youk J, Lee S, Min B, Lee S, Park W. Mater Lett 2006;60:757-60.

[12] Zhang L, Hsieh Y. J Nanosci Nanotechnol 2008;8:4461-9.

[13] Ma Z, Kotaki M, Ramakrishna S. J Membr Sci 2005;265:115-23.

[14] Lee K, Jeong L, Kang Y, Lee S, Park W. Adv Drug Deliv Rev 2009;61:1020-32.

[15] Liu H, Hsieh Y. J Polym Sci B Polym Phys 2002;40:2119-29.

[16] Tungprapa S, Puangparn T, Weerasombut M, Jangchud I, Fakum P, Semongkhol S, et al. Cellulose 2007;14:563-75.

[17] Koombhongse S, Liu W, Reneker D. J Polym Sci B Polym Phys 2001;39:2598-606.

[18] Selling G, Biswas A, Patel A, Walls D, Dunlap C, Wei Y. Macromol Chem Phys 2007;208: $1002-10$ 